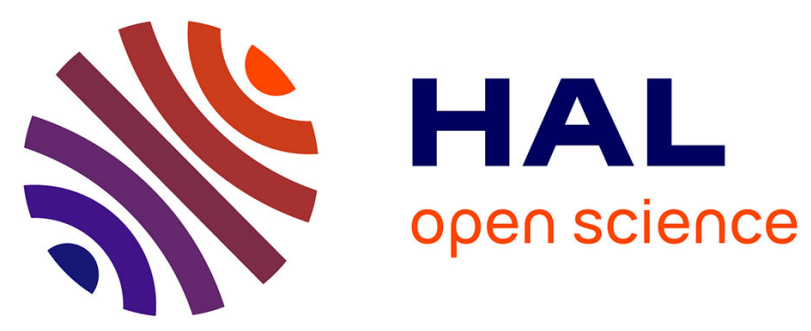

\title{
Correction of aerosol effects on multi-temporal images acquired with constant viewing angles: application to Formosat-2 images
}

Olivier Hagolle, Gérard Dedieu, Bernard Mougenot, Vincent Debaecker, Benoît Duchemin, Aimé Meygret

\section{To cite this version:}

Olivier Hagolle, Gérard Dedieu, Bernard Mougenot, Vincent Debaecker, Benoît Duchemin, et al.. Correction of aerosol effects on multi-temporal images acquired with constant viewing angles: application to Formosat-2 images. Remote Sensing of Environment, 2008, 112 (4), pp.1689-1701. 10.1016/j.rse.2007.08.016 . hal-00265400

\section{HAL Id: hal-00265400 \\ https://hal.science/hal-00265400}

Submitted on 20 Mar 2008

HAL is a multi-disciplinary open access archive for the deposit and dissemination of scientific research documents, whether they are published or not. The documents may come from teaching and research institutions in France or abroad, or from public or private research centers.
L'archive ouverte pluridisciplinaire HAL, est destinée au dépôt et à la diffusion de documents scientifiques de niveau recherche, publiés ou non, émanant des établissements d'enseignement et de recherche français ou étrangers, des laboratoires publics ou privés. 


\title{
Correction of aerosol effects on multi-temporal images acquired with constant viewing angles: application to Formosat-2 images
}

\author{
O. Hagolle ${ }^{1,2}$, G. Dedieu ${ }^{2}$, B. Mougenot ${ }^{2}$, V. Debaecker ${ }^{2}$, B. Duchemin ${ }^{2}$, A. Meygret ${ }^{1}$
}

1 CNES, 18 avenue Edouard Belin, 31401 TOULOUSE Cedex 4.Olivier.Hagolle@cnes.fr

2 CESBIO, Unité mixte CNES-CNRS-IRD-UPS, 18, avenue Edouard Belin, 31401 Toulouse Cedex 4, France

ABSTRACT - This paper presents a new method developed for the atmospheric correction of the images that will be acquired by the Venus satellite after its launch expected in early 2010. Every two days, the Venus mission will provide $10 m$ resolution images of 50 sites, in 12 narrow spectral bands ranging from $415 \mathrm{~nm}$ to $910 \mathrm{~nm}$. The sun synchronous Venus orbit will have a 2 day repeat cycle, and the images of a given site will always be acquired from the same place, at the same local hour, with constant observation angles. Thanks to these characteristics, the directional effects will be considerably reduced since only the solar angles will slowly vary with time.

The algorithm that will be implemented for the atmospheric correction of Venus data is being developed using both radiative transfer simulations and the actual data acquired by the Formosat-2 satellite. Because of its one day sun synchronous repeat cycle, Formosat-2 acquires images with a sun-viewing geometry close to the one Venus will offer. With this geometry, reflectance time series are free from directional effects on the short term, a feature which reduces the number of unknowns to retrieve. The atmospheric corrections algorithm exploits this feature and the two following assumptions:

- aerosol optical properties vary quickly with time but slowly with location.

- surface reflectances vary quickly with location but slowly with time.

Consequently, the top of atmosphere reflectance short term variations (10 to 15 
days) are mainly due to the variations of aerosol optical properties, and it is thus possible to use these variations to characterise the atmospheric aerosols and to retrieve surface reflectances.

This paper first describes the aerosol inversion method we developed and its results when applied to simulations. In a second part, we show the first tests of the method against three data sets acquired by Formosat-2 images with constant observation angles. Aeronet sun photometers measurements were available on all site. Formosat-2 estimates of optical thickness compare favourably with Aeronet in-situ measurements, leading to a noticeable improvement of the smoothness of time series of surface reflectances after atmospheric correction.

\section{INTRODUCTION}

Atmospheric correction is one of the key steps to obtain surface reflectances from space borne optical instruments operating in the visible and near infrared domain. The main difficulty of this processing is the correction of the effects of atmospheric aerosols, because their abundance and nature is highly variable in time and place. In the visible domain, the Top Of Atmosphere (TOA) reflectance above dark targets (dense vegetation cover for instance) may change by more than $100 \%$ when comparing a hazy day to a clear day. To perform accurate atmospheric corrections, a good knowledge of the Aerosol Optical Properties (AOP) is necessary.

Some sensors -e.g. MODIS (Remer et al, 2005) or POLDER (Deuzé et al, 2001)- provide "global" data sets of AOP, but only once or twice a day, and only for cloud free pixels. Since AOP and cloudiness change very quickly with time, it it is not only inaccurate but also sometimes impossible to use these data for then atmospheric correction of images 
acquired at a different hour. Moreover the accuracy of these estimates is not perfectly suited to perform an atmospheric correction: for instance POLDER products are only sensitive to fine aerosols (Deuzé et al, 2001) whereas MODIS products are not provided above bright surfaces Lastly, these products are delivered at a very coarse resolution : 10 $\mathrm{km}$ for MODIS, $21 \mathrm{~km}$ for POLDER.. A convenient alternative is to use the sensor imagery itself to detect aerosols and correct for their effect. However, the inversion of AOP from remote sensing images is not an easy task, especially above land. The difficulty can be explained easily with equation (1), which is a first order approximation of the atmospheric radiative transfer :

$$
r_{T O A}=t_{g} \cdot\left(r_{\text {surf }} \cdot T_{\text {atm }}(A O P)+r_{\text {atm }}(A O P)\right)
$$

where $r_{T O A}$ is the TOA reflectance, $r_{\text {surf }}$ is the surface reflectance, $T_{a t m}$ is the atmospheric transmittance due to any extinction process other than the absorption of the direct beam by atmospheric gases are respectively the atmospheric transmittance due to any extinction or scattering process other than the absorption of the direct beam by atmospheric gases, $r_{a t m}(A O P)$ is the atmospheric path reflectance, and $t_{g}$ is the transmission of molecular gases in the atmosphere. In this equation, for the sake simplification, multiple scattering is neglected and gaseous transmission is computed separately,

In this equation, for each measurement of $r_{T O A}$, we have two unknowns, the surface reflectance and the AOP, the gaseous transmission being accurately predicted using weather analyses (from the European Centre for Medium range Weather Forecasting (ECMWF) for instance) and ozone measurements from satellites (TOMS (Total Ozone Mapping Scanner) or OMI (Ozone Monitoring Instrument)). Despite this difficulty, the inversion of AOP has been attempted using various methods that require assumptions 
and advanced measurement techniques to determine simultaneously the surface reflectance and the AOP.

The sensors of POLDER family enable to invert aerosols thanks to multi-directional measurements of light polarisation (Deuzé et al, 2001). This method relies on the hypothesis that the earth surface polarisation is very low and can be well predicted. It gives very good results for aerosols made of small particles, but poor results for the larger particles such as desert dust.

Multi-directional measurements of reflectances are used to invert AOP with the ATSR sensor family (North, 2002) or with MISR sensor (Diner et al 2005). Here the estimation of AOP relies on the hypothesis of similarity of the shape of the bidirectional reflectance (BRF) between the NIR (MISR) or SWIR (ATSR) and the visible spectral bands.

Another family of algorithms assumes a spectral relationship between surface reflectances measured in two or more spectral bands (Remer et al, 2005). These methods are usually not very efficient on bright targets, and work better if a Short Wave Infra Red (SWIR) band is available. However, some interesting results have been obtained with MERIS sensor that has a set of spectral band very close to Venus' (Guanter, 2007, von Hoyningen-Huene, 2003).

Our work focuses on the atmospheric correction of the images acquired by the Venus satellite, scheduled to be launched in 2010. The Ven $\mu$ s mission (Dedieu et al, 2006) is a scientific mission in cooperation between the Israeli Space Agency (ISA) and the French Centre National d'Etudes Spatiales (CNES). Its aim is to demonstrate the usefulness of repetitive acquisitions of high resolution images for the monitoring of the dynamics of land surfaces. Fifty sites around the world will be imaged by Venus, every second day, for two years. The resolution of Venus products will be $10 \mathrm{~m}$, with a field of view of $27 \mathrm{~km}$. The instrument will deliver images in 12 narrow spectral bands ranging from $415 \mathrm{~nm}$ to 910 
$\mathrm{nm}$. One important characteristic of Ven $\mu$ s images is that a given site will be acquired with constant observation angles, at a constant local hour, thus minimizing directional effects: only sun angles, but since the satellite is on a sun-synchronous orbit, the variation within a month is just a few degrees.

As a consequence of this mission concept, the methods relying on the use of polarisation measurements, multi-directional observations or SWIR observations cannot be applied to Venus. But Venus has a unique feature that may be used to invert aerosols: the ability to make measurements with a 2-day revisit period and constant viewing angles in 12 narrow spectral bands. The constant observation angles enable to minimize the directional effects, and usually, surface reflectance does not change a lot during a couple of days. Consequently, TOA reflectance variations during a couple of days are mainly related to atmospheric effects. Such a property was investigated with Landsat by Tanré et al, (1988), but the study focused on the blurring effects and not on the reflectance variations because of the long time lag between two successive acquisitions.

Recent studies have shown the potential of using the short term temporal stability of surface reflectances to determine atmospheric properties from large field-of-view sensors (Lyapustin et al , 2007, Popp et al, 2006). Both studies provide good results in estimating simultaneously AOT and surface reflectances although their authors had to cope with the difficulties resulting from changing viewing angles (MODIS) or from coarse spatial resolution (MSG/SEVIRI). For Venus, thanks to the constant viewing angle and the high resolution, it is possible to use the following assumptions:

- the aerosol optical properties (AOP) vary quickly with time but usually slowly with location.

- the surface reflectance varies quickly with location but slowly with time (with exceptions that need to be detected before aerosol inversions). 
According to the above assumed properties, any quick variation of TOA reflectance is very likely to be due to a variation of AOP: this offers the opportunity to estimate the aerosol properties, and is the basis of our method for AOP retrieval.

The method planned for Venus is explained and tested using simulated data in $\$ 2$, then results obtained with Formosat-2 images are shown in $\$ 3$. Formosat-2, a satellite owned by the Taiwan National Space Organisation (NSPO), was launched in May 2004. It provides images with features very close to Venus: spatial resolution of $8 \mathrm{~m}$ in four spectral bands centred at 488, 555, 650 and $830 \mathrm{~nm}$, field of view of $24 \mathrm{~km}$, orbital cycle of one day, constant observation angles. We used three series of Formosat-2 images which were acquired with a revisit time of 3 or 4 days during 7 to 12 months over 3 sites with very different landscapes. The AOP inverted from the images are compared to the measurements collected with Aeronet sun photometers for each site.

\section{AOP INVERSION METHOD}

\subsection{Atmospheric Model}

The atmospheric model we use in this study is the Successive Orders of Scattering code (Deuzé et al, 1988). This code provides look-up tables (LUT) to compute top of atmosphere reflectance as a function of surface reflectances for different values of the following parameters :

- aerosol properties (Optical thickness and aerosol model)

- viewing and solar angles

- wavelength

- surface altitude

This first LUT is called "direct atmospheric model".

In a second step, these look-up tables are inverted to deliver surface reflectances as a function of TOA reflectances for the same parameter values as above. This inversion is 
done by fitting a $3^{\text {rd }}$ degree polynomial on the LUT values $\left(r_{\text {surf }} \Rightarrow r_{\text {TOA }}\right)$ for each combination of the other parameters (AOP, angles, wavelength, altitude). This second LUT is called "inverse atmospheric model".

The so-called "adjacency effect" (Tanré et al, 1981), related to the blurring of images by light scattered by the atmosphere, is not addressed in this study. Although not negligible, this phenomenon has a second order effect that will be addressed in future versions of the algorithm.

\subsection{Simulations}

To design and test the AOP inversion methods, a simple simulator of TOA reflectance time series has been developed. The time series are generated in two steps:

- First, surface reflectance time series are simulated for a whole season, hence with varying sun angles, and for a given viewing angle configuration, using SAIL radiative transfer model (Verhoef et al, 1984), coupled with the PROSPECT (Jacquemoud et al, 1990) and SOILSPECT (Jacquemoud et al, 1992) models that provide the Bidirectional Reflectance Distribution Functions (BRDF) of leaves and soil, respectively. Surface reflectance time series are simulated for all Venus spectral bands and for 50 pixels with different Leaf Area Index (LAI), whereas the other simulation parameters (chlorophyll and dry matter content, soil reflectance) are constant for all pixels. In the general case, LAI values are randomly chosen between 0.1 and 5, while a degraded case is studied with LAI randomly chosen between 0.1 and 0.3 . Then some "landscape noise" is added to account for short term variations of surface reflectances. This noise is simulated by a Gaussian random noise, and the robustness of the aerosol inversion has been tested against several values of the standard deviation of "landscape noise" ( $\mathrm{cf} \$ 2.4$ ). 
- Then, our direct atmospheric model is applied to obtain TOA reflectances, using a constant aerosol model with an aerosol optical thickness (AOT) that varies randomly as a function of time: the random AOT ranges from 0.1 to 0.7 , following a uniform probability law. The aerosol model has a log normal size distribution with a modal radius of $0.10 \mu \mathrm{m}$ and a refraction index of 1.44-0.003i, i.e. close to the continental category defined by Omar et al. (2005). Finally, some random noise is added to the TOA reflectances to account for instrumental noise and registration errors: Venus signal to noise ratio (SNR) is required to be better than 100 at 10 m resolution, but since the AOP will be inverted at a reduced resolution (100 m, cf chapter 3), we used a SNR equal to 400 . The instrument SNR also includes the effect of registration errors, but in fact these errors are not an issue with Formosat and Venus since the aerosol estimation method will work at 100 meter resolution, whereas the standard deviation of registration errors is below half a pixel (4m for Formosat) (Baillarin et al, 2004).

\subsection{Evaluation of Cost Functions}

Our AOP inversion method is based on the minimization of a cost function : in this study, we have successively experimented two different cost functions which are presented hereafter. The cost function are minimised using a non linear least-squares method, based on Levenberg-Marquardt algorithm.

$$
\text { Cost }=\sum_{i, i, \lambda}\left(\operatorname{atm}_{\operatorname{cor}}\left(r_{T O A}(i, j, \lambda, D), A O P(D)\right)-a \operatorname{atm}{ }_{c o r}\left(r_{T O A}(i, j, \lambda, D+2), A O P(D+2)\right)\right)^{2}
$$

Equation 2 (illustrated by Fig. 1) shows our first cost function, directly derived from the properties described at the beginning of this chapter. In this equation, $\lambda$ is the wavelength, (i,j) are the coordinates of pixels belonging to a neighbourhood, atm $\mathrm{cor}_{\text {in }}$ is the inverse atmospheric model that enables to estimate surface reflectances from TOA 
reflectances. The AOP are estimated for a neighbourhood of pixels, assuming that the AOP are constant within this neighbourhood. Let us assume the Venus acquisitions of day $\mathrm{D}$ and $\mathrm{D}+2$ are cloud free for this neighbourhood (if it is not the case, one can use $\mathrm{D}+4$ or $\mathrm{D}+6 \ldots$... Within such a short duration, the surface reflectances should not change: we can therefore search the AOP of day D and D+2 that minimise the sum of squares of the differences of the surface reflectances of day D and day D+2. In this inversion, we have two unknowns: the AOP of days $\mathrm{D}$ and $\mathrm{D}+2$, and many equations: one equation per pixel $(\mathrm{i}, \mathrm{j})$ and per spectral band $(\lambda)$. As previously mentioned, the atmospheric correction is performed using look-up tables (LUT) built with the Successive Orders of Scattering (SOS) code (Deuzé, 1998), the aerosol model is fixed, and the only parameter to estimate is the Aerosol Optical Thickness (AOT).

Figure 2 shows the results of AOT inversions based on our simulated time series, for two values of the landscape SNR. When the landscape and instrument SNR are equal to 400, the inversions are quite accurate except when the difference in AOT between two consecutive images is below 0.1. When the AOT difference is high, the estimated AOT for day $\mathrm{D}$ and $\mathrm{D}+2$ are accurate without using any a priori knowledge on the AOT of day D. When the AOT difference is low, the AOT estimate are not accurate any more. This was expected since the method has an important drawback: when two successive acquisitions have nearly identical AOP, our method is undetermined, since, when TOA reflectances of day D and D+2 are identical, any constant value of the AOT produces identical surface reflectances. Furthermore, one can note that in most cases, when the AOT difference is low, the retrieved AOT is below the 1:1 line: this is due to the nonlinearity of the atmospheric model. The origin of this phenomenon is given in Appendix 1. The plot on the right of Figure 2 shows that when the noise is increased, a higher value of the AOT difference is needed so that the AOT estimates stay accurate. 
To cope with the problem highlighted in figure 2 in case of low AOT difference, we have tested a more complex cost function (Equation 3, Figure 3). The first term of Equation 3 ( $1^{\text {st }}$ line) is equation 1: we search for AOPs of day D and D+2 in order to minimise the differences between surface reflectances of day D and D+2. But two terms were added $\left(2^{\text {nd }}\right.$ and $3^{\text {rd }}$ lines) to minimize the differences with an a previous knowledge of surface reflectances: $r_{\text {surf }}(i, j, \lambda, D)$. This reflectance comes from a previous iteration of this algorithm using days D-2 and D. K is a weighting coefficient which is proportional to the average variation of $r_{T O A}$ between day $\mathrm{D}$ and $\mathrm{D}+2$. If the $\mathrm{AOP}$ of day $\mathrm{D}$ and $\mathrm{D}+2$ are different, the value of $\mathrm{K}$ is large, the first line of equation 3 is preponderant and the method works as for equation 2. If the value of $\mathrm{K}$ is low, the use of the a priori reflectance still enables to invert the AOT. The initial a-priori surface reflectance is obtained by applying atmospheric corrections to the first image of the time series with an arbitrary AOT. The value of $\mathrm{K}$ controls the convergence rate, with quicker convergence for large $\mathrm{K}$ values, but when $\mathrm{K}$ is large, the inversion is more sensitive to landscape or instrument noise.

Of course, $r_{\text {surf }}(i, j, \lambda, D)$ has to be initialised for the first date of the time series : to obtain this initial value, the inverse atmospheric model is applied to the first image of the time series, with an a priori value of the AOP.

$$
\begin{aligned}
\text { Cost }=K . \sum_{i, j, \lambda} & \left(\operatorname{atm}_{c o r}\left(r_{T O A}(i, j, \lambda, D), A O P(D)\right)-\operatorname{atm}_{c o r}\left(r_{T O A}(i, j, \lambda, D+2), A O P(D+2)\right)\right)^{2} \\
& +\sum_{i, j, \lambda}\left(\operatorname{atm}_{c o r}\left(r_{T O A}(i, j, \lambda, D), A O P(D)\right)-r_{\text {surf }}(i, j, \lambda, D)\right)^{2} \\
+ & \sum_{i, j, \lambda}\left(\operatorname{atm}_{\operatorname{cor}}\left(r_{T O A}(i, j, \lambda, D+2), A O P(D+2)\right)-r_{\text {surf }}(i, j, \lambda, D)\right)^{2}
\end{aligned}
$$

This new cost function has been applied to invert the AOT on our simulated data set. For this inversion, the initial surface reflectance was intentionally biased by introducing an 
error of 0.15 on the AOT of the first day. Figure 4 shows that the algorithm converges after a few days and that the inversion works well for consecutive days with similar AOT. Table 1 shows the standard deviation of the AOT and surface reflectance obtained for various values of the standard deviation of "landscape noise". The increase of "landscape noise" causes an increase of the standard deviation of AOT errors and an increase of the bias. This phenomenon is still related to the non-linearity of the atmospheric model, explained in Appendix 1. Table 1 also clearly shows that the aerosol inversion uncertainty suddenly increases when landscape signal to noise ratio is worse than 100. Consequently, a detection of surface changes should be implemented to limit the "landscape noise" due to short term evolution of surface reflectances.

\subsection{Sensitivity studies}

Because of the lack of realism of our simulations of surface reflectance time series, it is not easy to perform a real error budget. However, we have studied the influence of various degradation causes on the accuracy of the results. The results are shown on table 2 and are to be compared to the nominal case (first line of table 2 which corresponds to the second line of Table 1).

For the simulations shown in table 1, a very optimistic hypothesis was used: the aerosol model in the simulations was the same as in the inversion. Table 2 /case 1 shows the results obtained when using different aerosol models: a log normal size distribution with a modal radius of $0.10 \mu \mathrm{m}$ and a refraction index of 1.44-0.003i for the simulations, and a $\log$ normal size distribution with a modal radius of $0.07 \mu \mathrm{m}$ and the same refraction index for the inversion (or conversely). The results show that the AOT estimation is biased but that the standard deviation of AOT does not increase much. Concerning surface reflectance errors, the performances for green and blue bands are not degraded by the 
errors on the aerosol model, but, as expected, the errors for NIR band increase a lot because the extrapolation of the aerosol optical properties from $550 \mathrm{~nm}$ to $850 \mathrm{~nm}$ is false.

In the simulations of the nominal case, the AOT ranges in $[0.1,0.8]$ interval. Case 2 studies the impact of a lower variation range $([0.1,0.5])$. As shown on Figure 2, our method works better when there are great variations of the AOT. As a result, the standard deviation of AOT in this case is slightly degraded.

Case 3 corresponds an AOT range of [0,0.7]. In this case, the bias of estimates disappears and the standard deviation is also reduced a little. The reason for this is that our inversion algorithm does not allow negative estimates of AOT. Suppose that the AOT has a negative bias equal to 0.05 : when a very low AOT appears in the simulations, the biased estimate should be negative, but because of the constraint to be positive, the estimate for the AOT is zero, which reduces the bias.

We have also studied (Table 2/case 4), the impact of using only one spectral band (green band at $550 \mathrm{~nm}$ ) to invert the optical thickness, instead of 2 spectral bands in the nominal case (450nm and $550 \mathrm{~nm}$ bands). In this case the performances are slightly degraded both for AOT estimates and surface reflectance. Of course, when using 2 spectral bands, the sensitivity to noise is reduced. For Ven $\mu$, at least 5 spectral bands (412, 443, 490, 565 and $620 \mathrm{~nm}$ ) will be available for AOT estimates, and the performances should thus be enhanced.

Case 5 corresponds to a $5 \%$ error on the absolute calibration of the sensor : the TOA reflectances are 5\% higher than what they should be. The consequences are an overestimation of surface reflectances, but the AOT error is only slightly increased.

Case 6 corresponds to the use of a more uniform landscape than in the nominal case : since our method needs contrast to converge quickly, a degradation of performances is 
expected. In the nominal case, the LAI of the 50 simulated pixels ranged between 0.1 and 5. For case 4 , we used a range of $[0.1,0.5]$. As a result, the standard deviation of the surface reflectance in the simulated neighbourhood was decreased from 0.04 to 0.01 in the green spectral band; this case corresponds to a very degraded case since such a uniformity of surface reflectance is quite rare. Results show some increase of the standard deviation of AOT estimation errors, and above all a bias on the AOT. The information content being poorer because of the uniformity of surface reflectances, the sensitivity to noise is worsened. Consequently, our method will be less accurate on uniform landscapes such as deserts. A way to mitigate this problem would be to increase the number of pixels used for AOT inversion when the landscape is uniform, in order to have more chance to collect different values of surface reflectances.

The last case study corresponds to brighter surface reflectances. A reflectance offset of 0.1 has been added to all the surface reflectances obtained for the nominal case. The surface reflectance in the green band now ranges in the interval $[0.19,0.23]$ instead of $[0.09,0.13]$. When surface reflectances are brighter, the estimate of AOT is slightly noisier and more biased. As expected,the sensitivity of TOA reflectance to the AOT is better when the surface reflectance is dark : as shown by equation 1, when the AOT increases, the atmospheric path reflectance increases but the transmittance decreases. Consequently, when the surface reflectance is dark and the AOT increases, the decrease of transmittance has a very low impact, whereas, for a brighter surface reflectance, the transmittance decrease can compensate the atmospheric path radiance increase. 


\section{Results obtained with Formosat-2 data}

The method based on the second cost function (eq. 3) has been applied to three different time series of Formosat-2 images. The first time series is located at an irrigated agricultural site in Tensift valley (Morocco), the second one is in an agricultural region next to Muret near Toulouse (France), with a mixture of winter and summer crops, and the third one is in Provence, near La Crau (France), with very varied landscapes: from agricultural zones to rice fields, with a quasi-desert flat area covered by stones and some grass. Formosat 2 images have been acquired above these sites every third or fourth day during 7 to 12 months. For Tensift, the images were acquired with a Viewing Zenith Angle (VZA) of $21^{\circ}$ in the backscattering direction, for Muret, the VZA is $22^{\circ}$ in the forward scattering direction, and for La Crau, the VZA is $41^{\circ}$ in the orthogonal plane.

For the three sites, Aeronet sun photometer data were available. The sun photometer was directly on the site for Muret (Toulouse Aeronet site). For Tensift, a sun photometer was available at a distance of $50 \mathrm{~km}$ for the November-February period (Saada Aeronet site), and then directly on the site (Ras el Ain Aeronet site). For La Crau, the Avignon Aeronet site( $50 \mathrm{~km}$ North of La Crau) was used from March to May, then the sun photometer was transported directly to La Crau site.

The preprocessing of Formosat-2 data is described hereafter. First, the Formosat-2 images are geolocated, registered, calibrated, and the clouds and their shadows are discarded. The absorption by atmospheric molecules is corrected using the SMAC method (Rahman and Dedieu, 1994) and average values of ozone, oxygen and water vapour concentrations. Formosat-2 images are then sub-sampled to $100 \mathrm{~m}$ resolution in order to reduce noise and registration errors, and to smooth very local variation of 
surface reflectances. Then, a neighbourhood of $7 x 7$ pixels of $100 \mathrm{~m}$ resolution is extracted around the Aeronet sun-photometer location.

For all the pixels of this neighbourhood, a detection of fast varying surface reflectances is applied. This detection is based on a threshold on the variation of near-infrared TOA reflectance between two consecutive images. Since the near infrared band is not too sensitive to the aerosol content, a high variation of the TOA reflectance is very likely to come from variations of surface reflectance. The detected variations come from human interventions such as ploughing or harvesting, from the darkening effect of rain on bare soil, or from quick vegetation development in spring. Our algorithm is applied only to the pixels in the neighbourhood that are not affected by clouds or by fast variations of surface reflectance. If the number of clear and stable pixels in the neighbourhood is too low (less than 50\%), aerosol inversion is not attempted (this happens for instance on Tensift site after heavy rain events).

Only two Formosat-2 spectral bands, centred at 488 and $560 \mathrm{~nm}$, are used for the inversion, because these bands are very sensitive to aerosol effects, and in most cases, the surface reflectance of these bands varies slowly. This assumption does not hold for 650 and $830 \mathrm{~nm}$ bands, as it may be seen on the time series plotted on Figure 5, 6 and 7; if we use these two spectral bands, the retrieved AOT tends to be much more sensitive to surface reflectance variations.

Given the low number of available spectral bands, we try to invert the AOT only, and we use a constant aerosol model for all the sites and all the dates. This model is the continental one described in $\$ 2.2$ (simulations). The a priori reflectance of the first date of the 3 time series was initialised by applying an atmospheric correction to the TOA reflectance of the first date, assuming the AOT is 0.2 and the aerosol model is the 
continental one. For each Formosat-2 date, two estimates of the AOT value are obtained : one when the image is used as date $\mathrm{D}$ and one as date $\mathrm{D}+2$.

Figures 5, 6 and 7 show time series of AOT along with top of the atmosphere and surface reflectances near the three Aeronet sites in Tensift (Morocco), Muret (France) and La Crau areas. For the Muret data set, 3 plots are given that correspond to various land covers: a sunflower crop, a maize crop and a deciduous forest. Since there is only one sun-photometer in the area covered by the images, The AOT at $550 \mathrm{~nm}$ obtained on these 3 neighbourhoods are compared to the Aeronet AOT assuming that the optical thickness does not change a lot in a few kilometres. The AERONET AOT are obtained from level 1.5 AERONET data (cloud screened data), after interpolation at $550 \mathrm{~nm}$ and temporal average of in situ measurements collected in a one hour period centred on the satellite acquisition time. The error bars on the aerosol estimates express the standard deviation of the AOT during these one hour periods. When only one or two measurements are available, a two hour period is used for averaging, but the standard deviation is arbitrarily multiplied by 10 , to underline that the measurement may be wrong because of the presence of clouds. For La Crau, two neighbourhoods in the quasi-desert area are used, one in the very uniform part, the other one close to the edge of La Crau "desert". The latter neighbourhood contains pixels from an orchard.

From with these 3 figures, we can draw the following conclusions:

- there is a good overall agreement between Aeronet and Formosat-2 AOT, except on Fig 5, Tensift site in the summer period, and on Fig 7 right (La Crau site). This is discussed in the commentaries of Figure 9.

- there is a good agreement in all figures between the Formosat-2 AOTs estimated when a given date is used as day $\mathrm{D}$ or day $\mathrm{D}+2$. 
- On Fig 5 left, an initial AOT value of 0.2 is used, whereas on Fig 5 right, the initial value is 0.4 . After one month, the AOT estimated by the algorithm do not depend any more on the initialisation value, showing a good convergence after an initial error.

- the AOT derived above various landscapes (e.g. forest on Fig 6 left and maize on Fig 6 right) are also quite consistent despite a distance of a few kilometres between the neighbourhoods.

- the TOA reflectance time series at $100 \mathrm{~m}$ resolution are already quite smooth, thanks to the constant viewing angle;

- $\quad$ surface reflectances in blue, green and red spectral bands are smoother than TOA reflectances (see for instance Fig 5 left (November/December) and Fig 6 (all dates)). On the contrary, the smoothness of Near Infra Red (NIR) spectral band is not much enhanced by the atmospheric correction, but in many cases the sudden variations observed on NIR reflectances are either due to surface reflectance sudden variations or to the presence of semi-transparent clouds that are considered as aerosols by our method. Some of the causes of sudden variations are pinpointed on the plots.

- As shown in the sensitivity study, when the surface is too uniform, the aerosol inversion does not converge to the accurate AOT values. This can be seen on Fig 7 right, that corresponds to the very uniform part of La Crau "desert”. However, even in this case, the relative variations of AOT still follow the Aeronet observations, and the surface reflectances are still smooth.

- some dates show suddenly larger TOA and surface reflectances in the NIR band: for instance, for the forest surface in Muret site, on September $9^{\text {th }}$ and November $18^{\text {th }}$ (Figure 6). While the surface reflectances in the visible bands after 
atmospheric correction are similar to the ones of the previous or next days, the contribution of thin clouds to the NIR reflectance is not well corrected. In fact, looking at the images (See Fig 8), we can see that these two dates are covered by semi transparent clouds that escaped the cloud screening because they are too thin. The extrapolation of the optical thickness measured in the blue and green bands to the NIR infrared via a continental aerosol model is of course inaccurate in the case of a thin cirrus cloud.

- Our Formosat-2 data sets have some long data gaps (more than a month for Muret) because of satellite unavailability, programming conflicts with other user requests, or cloud cover. One can note (Fig 6) that even in this case, the AOT retrieved on the day after the gap is close to the Aeronet value. In case of a longer data gap, a reinitialisation of the algorithm would be necessary.

Figure 9 shows a comparison between Aeronet measurements of aerosol optical thickness (AOT) and our retrievals using Formosat-2. The uncertainty of AERONET AOT retrieval is generally below 0.02 (Holben et al,1998), provided that the aerosol properties are stable with time or with the horizontal distance. When this is not true, additional uncertainty is added because the satellite and sun photometer measurements are not simultaneous, and are acquired with different observation directions. AOT variations of 0.05 in only one hour are often observed on our sites; on these plots, we have discarded the days when the AOT measured by Aeronet is not stable around Formosat 2 overpass time: a threshold of 0.03 on the AOT standard deviation was used.

The agreement between Aeronet and Formosat-2 AOT measurements is quite good, and for a given date, the aerosol estimates obtained when the date is used as day D or day D+2 are also very consistent. For Muret, the r.m.s. difference of AOT between Formosat-2 and Aeronet is around 0.08 , for La Crau, around 0.09, for Tensift valley it is around 0.12. 
The better performance for Muret is probably due to the lower surface reflectances observed in France compared to Tensift : indeed, the agreement between Formosat-2 and Aeronet AOT is improved during the agricultural season in the Tensift site (March to May), as it may be seen on Fig 5 left. The surface reflectances for Tensift site are also much more uniform in summer and convey less information for the inversion, as shown in the sensitivity study of $\$ 2.5$. Another reason of the worse results obtained for Tensift site in summer is the frequent presence of desert dust aerosols which behave very differently from the continental model we have used for the inversions.

We have also compared (Figures 10) the surface reflectances obtained after atmospheric corrections performed either with Formosat-2 AOT or Aeronet AOT or a constant AOT of 0.2. All the corrections are performed using the same constant continental aerosol model. The figures show that i) the three atmospheric corrections produce the same results for Near-Infrared band ii) the surface reflectance variations against time in the visible bands are smoother when AOT estimates are used, iii) surface reflectances obtained from Aeronet or Formosat-2 AOT estimates are very similar for Muret, some divergences are observed in summer for Tensift site. For Muret (Fig. 10 left), there are only a few cases when these estimates differ, in May or September 2006. In these few cases, the surface reflectance obtained with Formosat-2 AOT appears smoother in the blue band, but it is difficult to determine if the error source is the Aeronet AOT estimate or an error from our algorithm that may interpret small variations of surface reflectances as variations of AOT. For Tensift (Fig.10 right), the agreement on surface reflectances obtained with Formosat-2 and Aeronet is still good in winter and spring, but surface reflectances derived from Formosat-2-AOT are lower in summer. This period corresponds to the time when our method is less efficient because surface reflectances 
are higher and more uniform and because the assumption of a constant aerosol model is probably false.

On Fig 11, the surface reflectances obtained at La Crau "desert" site have been compared to the surface reflectances estimates provided by CNES automated calibration station (Schmechtig et al 1997, Meygret 2005). This station, named ROSAS (RObotic Station for Atmosphere and Surface) is made of a CIMEL photometer mounted on top of a post at $10 \mathrm{~m}$ above ground. The photometer is similar to the photometers used in the AERONET program; it just differs from them by its capacity to measure not only the downwelling radiance, but also the upwelling radiance. The photometer data are converted to surface reflectances following the method explained in (Meygret, 2005), and then interpolated to match Formosat2 spectral bands and viewing direction. Although ROSAS surface reflectances are somewhat noisy, they are consistent with the Formosat2 surface reflectances derived by our method, with maybe a little bias in the blue band.

\section{CONCLUSIONS}

We have developed a new method to invert aerosol optical properties from high resolution sensors with frequent revisit capacities and constant observation angles. The design phase of this algorithm was based on simulations: the simulations results showed that the method works well when the Aerosol Optical Thickness (AOT) varies significantly with time, but needs a regularization when AOT inversion is attempted with consecutive days with similar aerosol conditions. The cost function used in the inversion procedure has been modified to cope with this problem and the regularization proved successful. The simulations also showed how the performances of aerosol inversion are sensitive to noise and to quick surface reflectance variations: an averaging to reduce noise is necessary and it is not possible to use this method at full resolution. Moreover, an algorithm for detecting abrupt changes in surface reflectance is required. 
This method, designed for the Venus mission, has been applied to three time series of Formosat-2 images where Aeronet AOT measurements are available. The results are very satisfactory: the retrieved AOT agree well with in-situ measurements of Aeronet, and the surface reflectances are after atmospheric correction are consistent with in-situ measurements obtained in La Crau. In the visible spectral bands, the reflectances after atmospheric correction are much smoother than the TOA reflectances. However, the smoothness of near infrared surface reflectances is not so much improved by our atmospheric correction: part of the irregularities are due to vegetation cover changes or to undetected clouds, but part of the errors are also probably due to the use of a unique aerosol model for all sites and all dates. A limitation of the method was also observed when surface reflectances are spatially uniform or very bright: this method is probably not adapted to very uniform desert sites, or maybe only to retrieve relative variations of optical thickness. Despite these limitations, the definition level of our method is sufficient to begin its implementation in the future operational Venus level 2 processing. It may also be worth trying to apply it to other satellites with a high revisit frequency and constant observations angles: for instance, the weather geostationary satellites (MSG, GOES) as well as CNES's POLDER-2 mission have these features. ESA Sentinel-2 future mission (ESA, 2007) might also benefit from this method: although the revisit time is somewhat longer than Venus (5 days instead of 2) it should be sufficient for atmospheric correction in most cases, and the contribution of SWIR bands should help in detecting cirrus clouds (using $1.38 \mu \mathrm{m}$ band) and surface reflectance variations (using $1.6 \mu \mathrm{m}$ and $2.2 \mu \mathrm{m}$ spectral bands).

In this study, we only tried to invert the AOT with a fixed aerosol model. Of course, it would be interesting to try to invert simultaneously the aerosol model and the AOT from the image data, but this requires a sufficient number of spectral bands to constrain the 
aerosol model. In this respect, the four spectral bands of Formosat-2 do not provide enough information, but with the 12 spectral bands of Venus, or the spectral richness of Sentinel 2, this task should be easier. 


\section{APPENDIX : explanation of the bias observed in the AOT retrieval}

The bias observed on figure 2 is due to the fact that for a given surface reflectance, the amount of noise on the estimate of surface reflectance increases with the Aerosol optical thickness. This can be explained by the example of Fig 12 which is obtained as follows : suppose we have a uniform landscape with a surface reflectance of 0.1 . To obtain the corresponding TOA reflectance in Formosat blue band, we add atmospheric effects using the direct atmospheric model. In this example, we used an AOT at $550 \mathrm{~nm}$ equal to 0.1 (dashed line) and to 0.6 (solid line) to obtain TOA reflectances. Then a noise with a standard deviation of 0.02 was added to both TOA reflectances to obtain the blue histograms. Finally, atmospheric corrections are performed an AOT of 0.1 (dashed line) or 0.6 (solid line). The resulting solid histogram is broader than the solid one, showing that the standard deviation of noise after atmospheric correction increases when the AOT increases. This increase of standard deviation is due to the non linearity of the atmospheric correction, as shown on Fig 13.

Moreover, as the instrument noise we introduced in the simulations of $\$ 2.2$ is a multiplicative noise defined by a constant signal to noise ratio, more noise is added when the TOA reflectance is higher, thus when optical thickness is higher. The resulting noise as a function of optical thickness is the dashed line on Fig 13.

Fig 14 shows a plot of the function $\mathrm{F}$ of equation 4 : this function gives the value of the cost function of equation 2, as a function of the AOT of day D. This case function corresponds to an example simulation for which the AOT of the day D is 0.45 and the one of day D+2 is 0.75 . Two plots of this function are given, one in a case with no noise, and one in a case with landscape and instrument SNR of 400. The cost function of the noisy case is the sum of the cost function of the case without noise, and of the effect of noise on surface reflectance (dashed line). Since the amount of noise on the surface reflectances increases with the value of the AOT, the minimum value of the cost function in the noisy case is slightly shifted towards lower values of AOT. This explains the bias observed on Fig 2. Of course the bias is greater when the amount of noise increases or when the cost function is flat near the minimum, for instance when the AOT difference between consecutive images is low. 
$F(A O T(D))=\underset{A O T(D+2)}{\operatorname{minimum}}\left(\sum_{i, j, \lambda}\left(\operatorname{atm}_{\operatorname{cor}}\left(r_{T O A}(i, j, \lambda, D), A O T(D)\right)-\operatorname{atm}_{\operatorname{cor}}\left(r_{T O A}(i, j, \lambda, D+2), A O T(D+2)\right)\right)^{2}\right)$ equation (4)

\section{ACKNOWLEDGEMENTS}

The Formosat-2 images used in this paper are (C) NSPO (2006) and distributed by Spot Image S.A. all rights reserved. The geometric registration was done at CNES, and the authors want to thank S. Baillarin and CNES/SI/EI team (esp. Gregory Clement) for this processing. We are very thankful to the Aeronet Sunphotometer Network and want to acknowledge the help of INRA Avignon, for moving their Sunphotometer near La Crau site. At CESBIO, P. Richaume gave us very good advice for the mathematical part of this study and Vincent Simonneaux and Pierrette Gouaux kindly provided us with ground control points for image registration.

\section{REFERENCES}

1 G. Dedieu, A. Karnieli, O. Hagolle, H. Jeanjean, F. Cabot, P. Ferrier, Y. Yaniv, VEN $\mu$ S: A joint Israel-French Earth Observation scientific mission with High spatial and temporal resolution capabilities, second Recent Advances in Quantitative Remote Sensing symposium, Torrent, 25-29 september 2006

2 Holben, B. N., T. F. Eck, I. Slutsker, D. Tanre, J. P. Buis, A. Setzer, E. Vermote, J. A. Reagan, Y. J. Kaufman, T. Nakajima, F. Lavenu, I. Jankowiak, and A. Smirnov, Aeronet-A federated instrument network and data archive for aerosol characterization. Remote Sensing of Environment, 66, (1), 1-16, 1998

3 North, P.R.J. (2002), Estimation of aerosol opacity and land surface bidirectional reflectance from ATSR-2 dual-angle imagery: operational method and validation, J. Geophys. Res., 107(D12)

4 A method for the atmospheric correction of ENVISAT/MERIS data over land targets, L. Guanter, M. C. González, J. Moreno, International Journal of Remote Sensing, 709-728, 28, 2007

5 Remer, L. A., Y. J. Kaufman, D. Tanre, S. Mattoo, D. A. Chu, J. V. Martins, R. R. Li, C. Ichoku, R. C. Levy, R. G. Kleidman, T. F. Eck, E. Vermote, and B. N. Holben: The MODIS aerosol algorithm, products and validation. J. Atmos. Sci., 62, 947-973, 2005 
6 Deuzé, J. L.; Bréon, F. M.; Devaux, C.; Goloub, P.; Herman, M.; Lafrance, B.; Maignan, F.; Marchand, A.; Nadal, F.; Perry, G.; Tanré, D: Remote sensing of aerosols over land surfaces from POLDER-ADEOS-1 polarized measurements, Journal of Geophysical Research, Volume 106, Issue D5, p. 4913-4926, 2001

7 von Hoyningen-Huene, W.; Freitag, M.; Burrows, J. B.: Retrieval of aerosol optical thickness over land surfaces from top-of-atmosphere radiancen, Journal of Geophysical Research (Atmospheres), Volume 108, Issue D9, pp.AAC 2-1,2003

8 D. Tanré, C, Devaux; M. Herman, P Y; Deschamps, 1988, Estimation of Saharan aerosol optical thickness from blurring effects in Thematic Mapper data, Journal of Geophysical Research. Vol. 93, pp. 15955-15964.

9 Diner, DJ, JV Martonchik, R Kahn, 2005. Using angular and spectral shape similarity constraints to improve MISR aerosol and surface retrievals over land. Remote Sensing of Environment 94, no. 2: $155-171$.

10 Popp, C, N Foppa, A Hauser, et S Wunderle. 2006. Aerosol optical depth retrieval over land using METEOSAT-8 SEVIRI data. May. http://earth.esa.int/workshops/atmos2006/

11 Lyapustin, Alexei, et Yujie Wang. 2007. MAIAC: Multi_Angle Implementation of Atmospheric Correction for MODIS. MODIS Algorithm Theoretical Basis Document, NASA.

http://neptune.gsfc.nasa.gov/bsb/subpages/index.php?section=Projects\&content=SHARM

12 Deuze, JL, M Herman, et R Santer. 1989. Fourier series expansion of the transfer equation in the atmosphere-ocean system. Journal of Quantitative Spectroscopy and Radiative Transfer 41:483494.

13 Tanre, D., M. Herman, et PY Deschamps. 1981. Influence of the background contribution upon space measurements of ground reflectance. Appl. Opt 20 (20): 3676-3684.

14 Rahman, H, et G Dedieu. "SMAC: a simplified method for the atmospheric correction of satellite measurements in the solar spectrum." International journal of remote sensing. 15.1 (1994): 123143.

15 Jacquemoud, S, F Baret, et JF Hanocq. 1992. Modeling spectral and bidirectional soil reflectance. Remote Sensing of Environment 41 (2): 123-132.

16 Jacquemoud, S, et F Baret. 1990. PROSPECT: A model of leaf optical properties spectra. Remote Sensing of Environment 34 (2): 75-91.

17 Verhoef, Wout. 1984. Light scattering by leaf layers with application to canopy reflectance modelling: the SAIL model. Remote sensing of environment 16 (2): 125-141. 
18 Baillarin, S, JP Gleyzes, C Latry, A Bouillon, E Breton, L Cunin, et coll. 2004. Validation of an automatic image ortho-rectification processing. Geoscience and Remote Sensing Symposium, 2004. IGARSS'04. Proceedings. 2004 IEEE International 2.

19 Dubovik, O, A Smirnov, BN Holben, MD King, YJ Kaufman, TF Eck, et coll. 2000. Accuracy assessments of aerosol optical properties retrieved from Aerosol Robotic Network(Aeronet) sun and sky radiance measurements. Journal of Geophysical Research 105 (D8): 9791-9806.

20 Omar, AH, JG Won, DM Winker, SC Yoon, O Dubovik, MP McCormick, et coll. 2005. Development of global aerosol models using cluster analysis of Aerosol Robotic Network (Aeronet) measurements. Journal of Geophysical Research 110:D10S14.

21 Schmechtig, C, R Santer, JC Roger, et A Meygret. 1997. Automatic ground-based station for vicarious calibration. SPIE Europto conference Sensors, systems, and next-generation satellites:309-317 London.

22 Meygret, A. 2005. Absolute calibration: from SPOT1 to SPOT5. Proceedings of SPIE Optics and Photonics, August San Diego, California, USA. Vol 5882.

23 ESA. 2007. GMES Sentinel-2 mission requirement document. N EOP-SM/1163/MR-dr v2.0 http://esamultimedia.esa.int/docs/GMES/MRD_Sentinel_2.pdf 


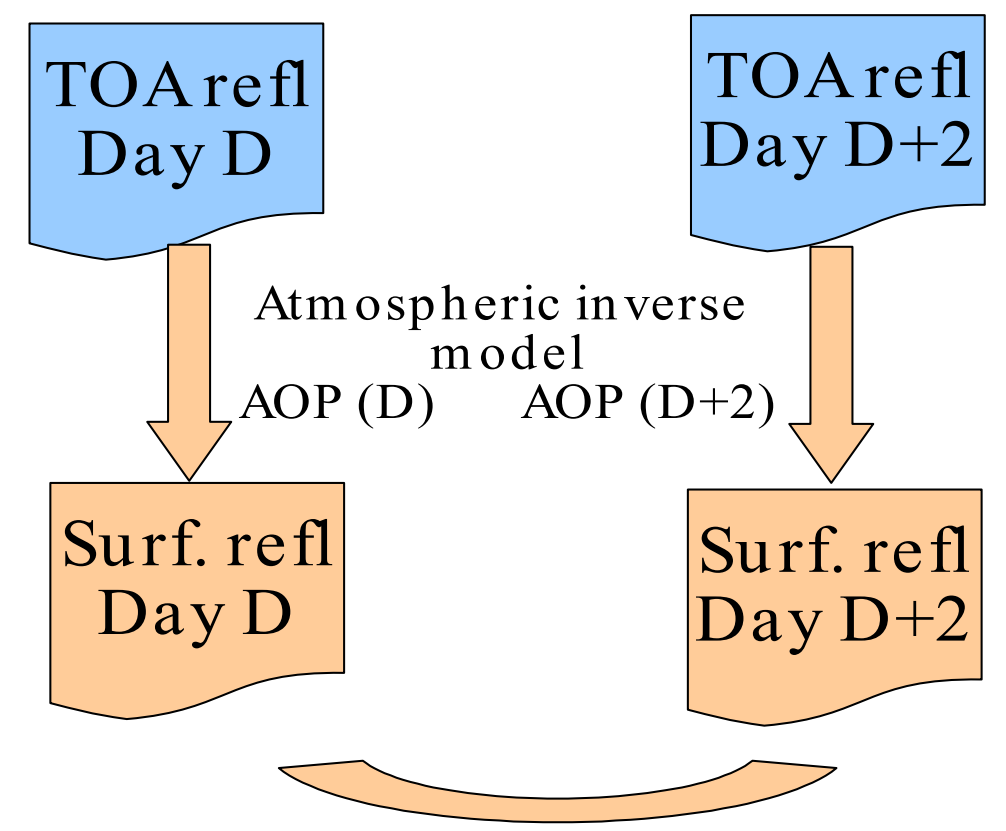

Figure 1: Scheme of a first version of aerosol inversion cost function, in the case of Venus, for which acquisitions will be available every second day. In this version, a Levenberg-Marquardt least squares minimization algorithm searches for the Aerosol Optical Properties of day D and D+2 that minimize the differences between the surface reflectances of day $D$ and $D+2$. 

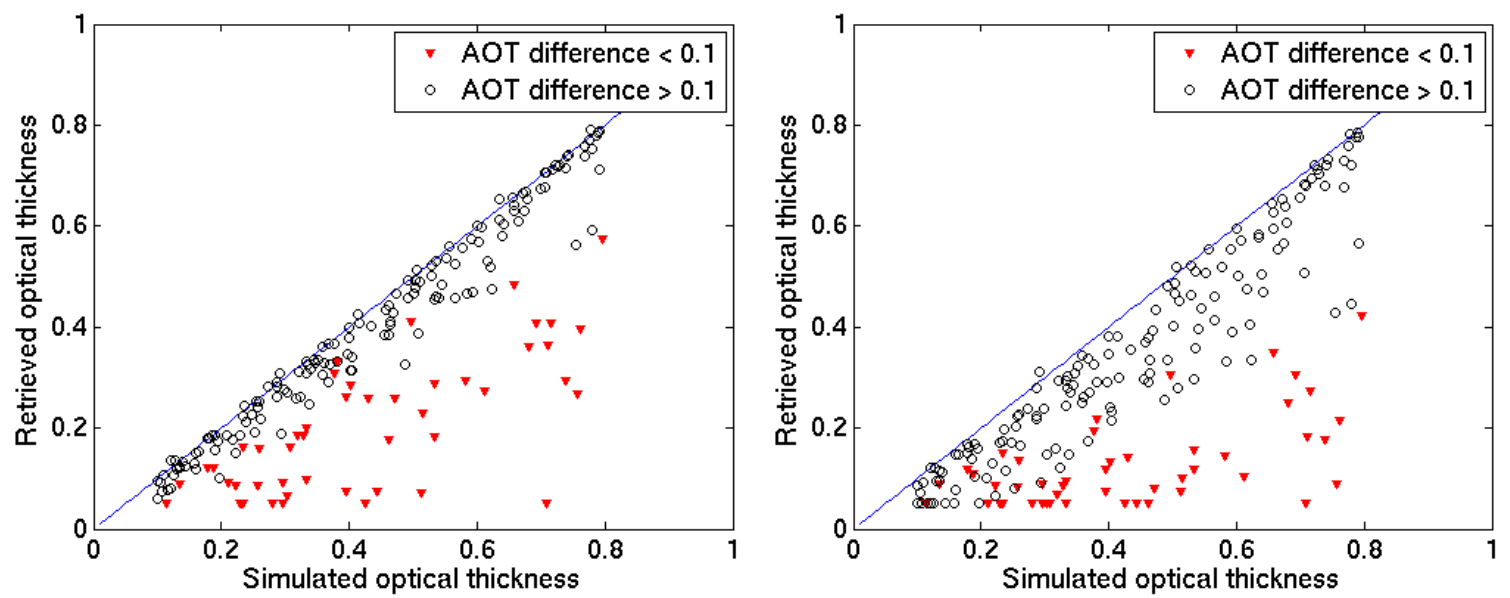

Figure 2: Inversion of Aerosol Optical Thickness (AOT) with simulated data. 200 days of top of atmosphere reflectances have been simulated with random AOT and a constant aerosol model, left with a landscape SNR of 400 and an instrument SNR of 400, right, with a landscape SNR of 100 and an instrument SNR of 400. The inversion of the AOT with the scheme on Fig 2 is correct when the difference of AOT for two successive days is greater than 0.1 (circles), but erroneous when the AOP difference is lower than 0.1 (filled triangles). 


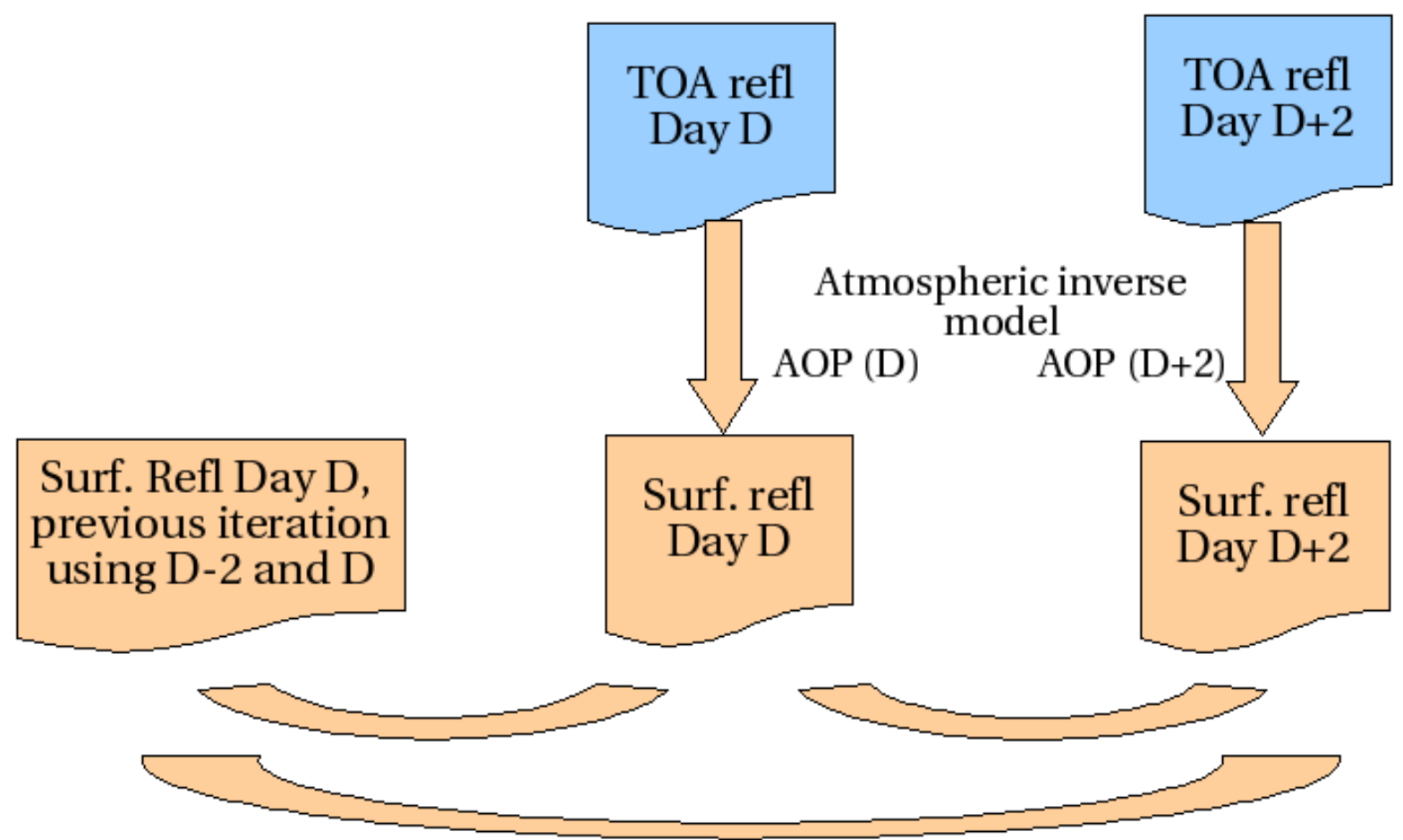

Figure 3: Scheme of the final version of aerosol inversion cost function. In this version, a LevenbergMarquardt least squares minimization searches for the Aerosol Optical Properties of day D and D+2 that not only minimize the differences between the surface reflectances of day $D$ and $D+2$, but also the differences of surface reflectances of day $D$ and $D+2$ with the surface reflectance of $D$ computed by the previous iteration of the algorithm (using the TOA reflectances of D-2 and D.) 

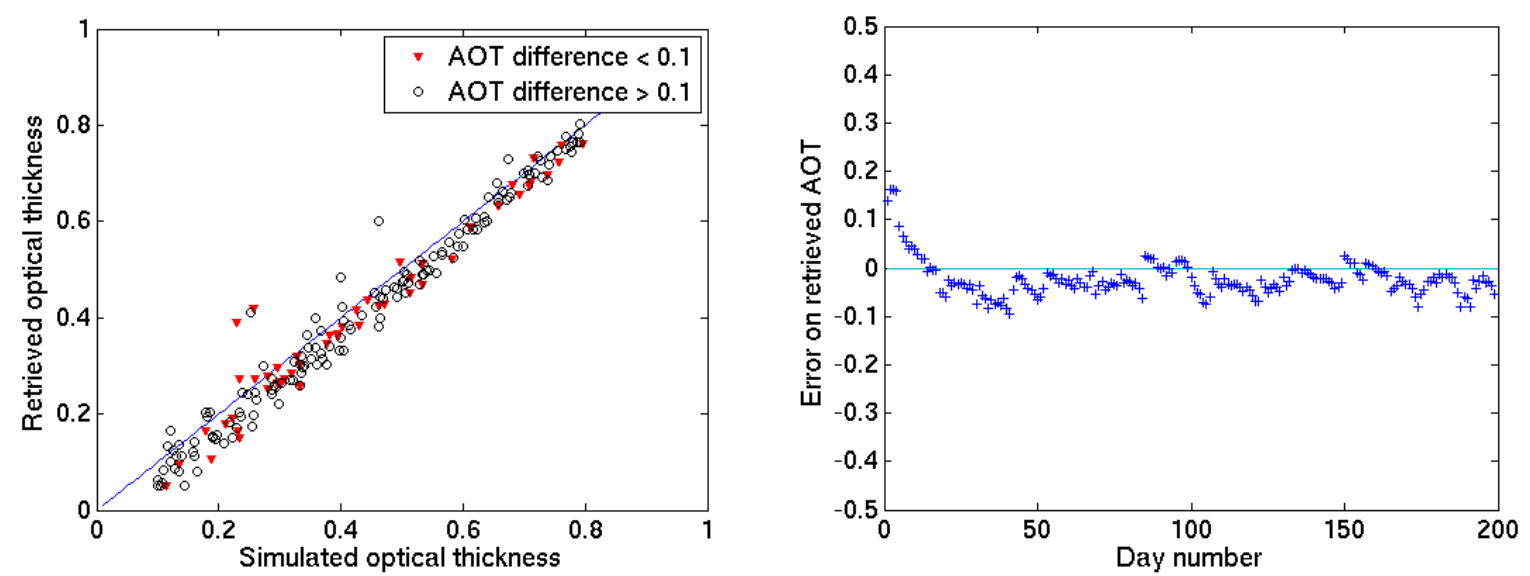

Figure 4: Results obtained with the same simulations as for Figure 2, but with the cost function described in Figure 3. The left plot shows that consecutive days with small AOT difference (triangles) behave similarly to higher differences. On the right, the error on the retrieved AOT is shown versus day number. This plot shows that after an initial error of 0.15, the retrieved optical thickness converges to the right value after the $10^{\text {th }}$ image. 

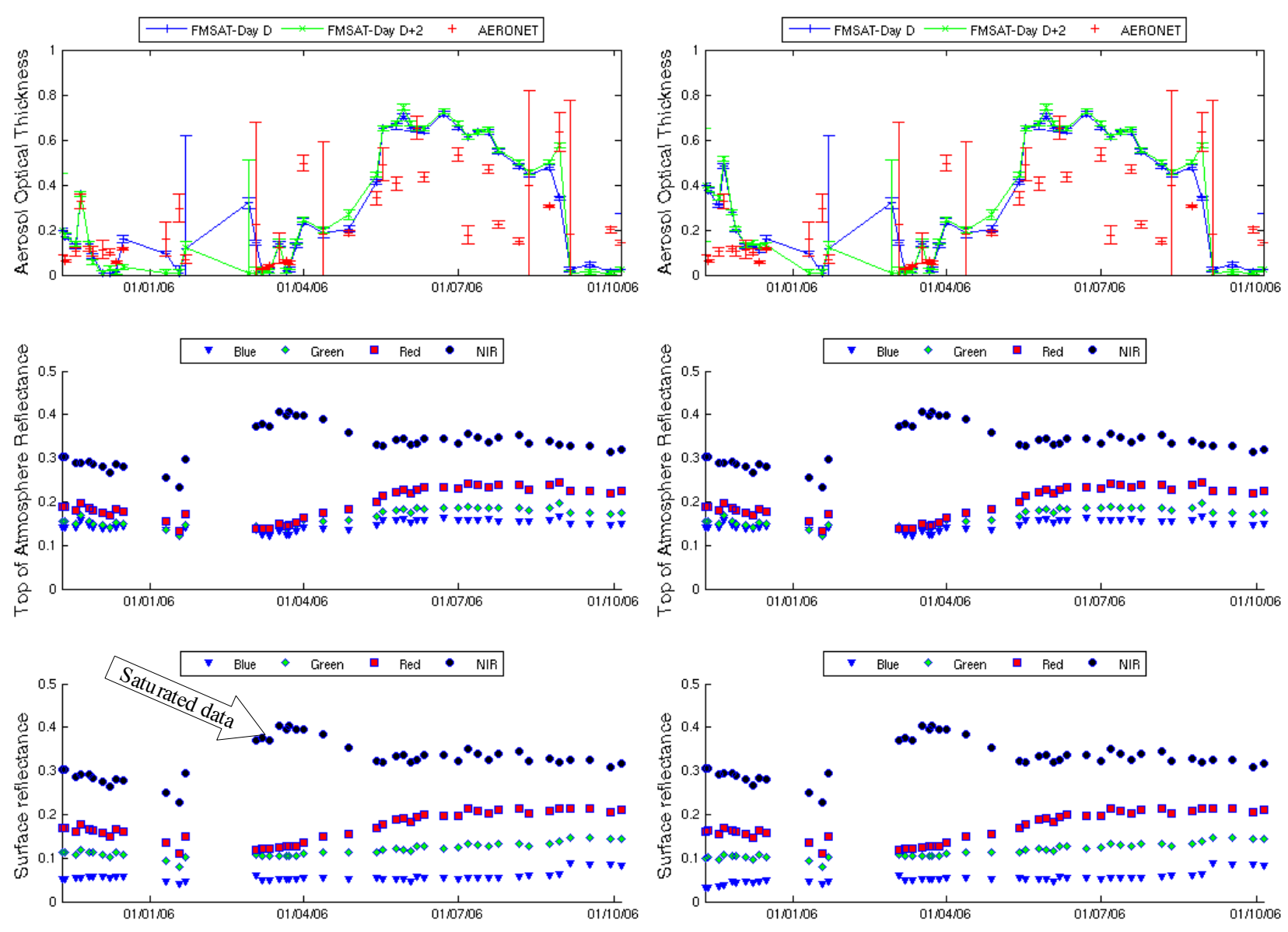

Figure 5: AOT and reflectances as a function of time, for a neighbourhood of pixels in Tensift data set (fallow/wheat mixture), left, for a nearly correct initialisation of AOT, right for an erroneous value. From top to bottom: 1) Retrieved AOT when the date is used as day $D$ (blue) or D+2 (green), compared to optical thickness derived from Aeronet (red).2) TOA reflectance for all Formosat-2 channels for the $100 \mathrm{~m}$ pixel at the neighbourhood centre, 3) surface reflectance obtained from TOA reflectance corrected using day D+2 AOT for the same $100 \mathrm{~m}$ pixel. For AOT, the error bars are shorter when the optical thickness is stable near Formosat-2 overpass time, and arbitrarily larger when very few measurements are available, indicating a strong likelihood of presence of clouds within the image. 

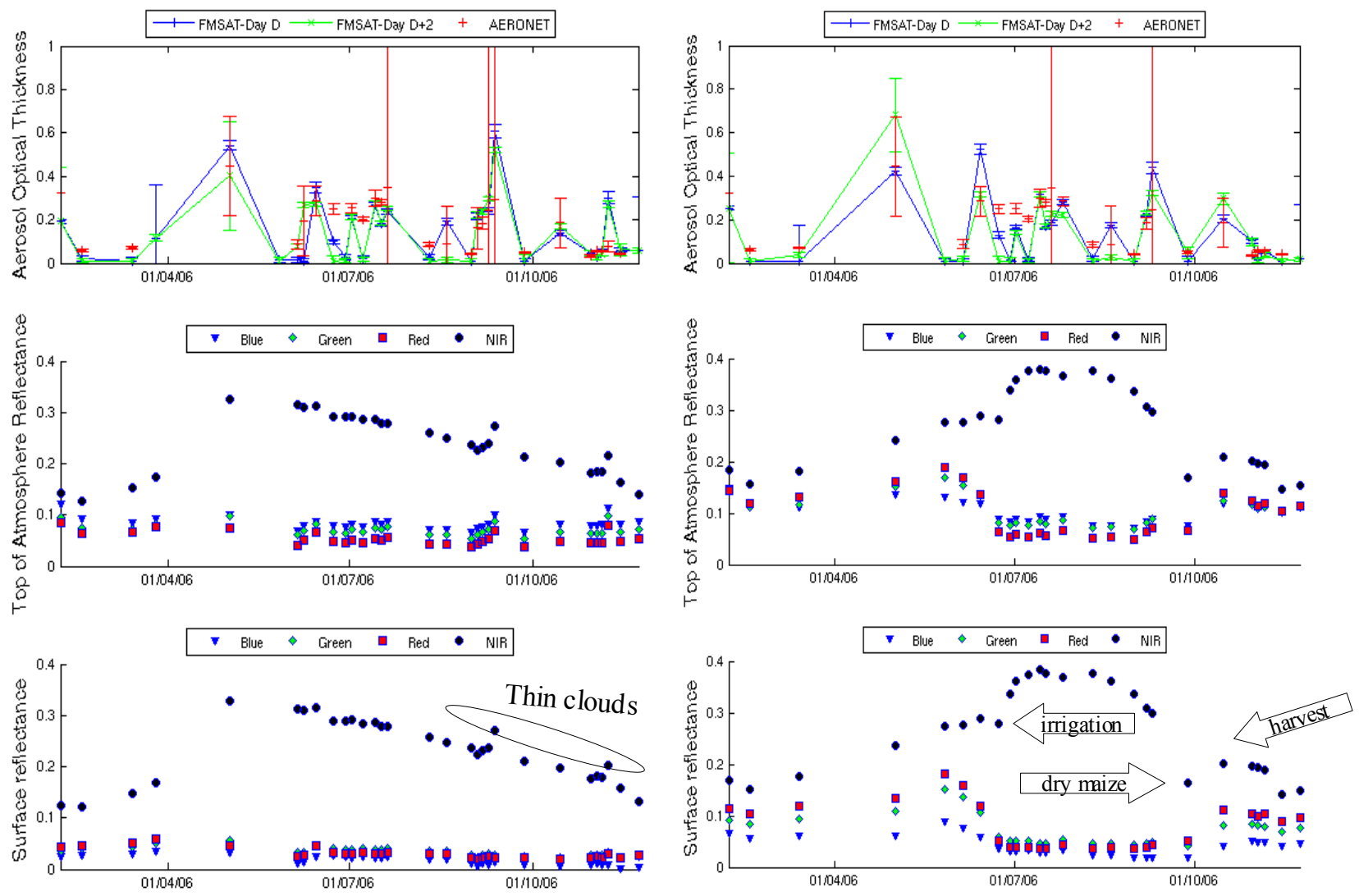

Figure 6: Same as Fig 5, left: for a deciduous forest pixel in Toulouse time series, right: for a maize pixel in Muret time series. 

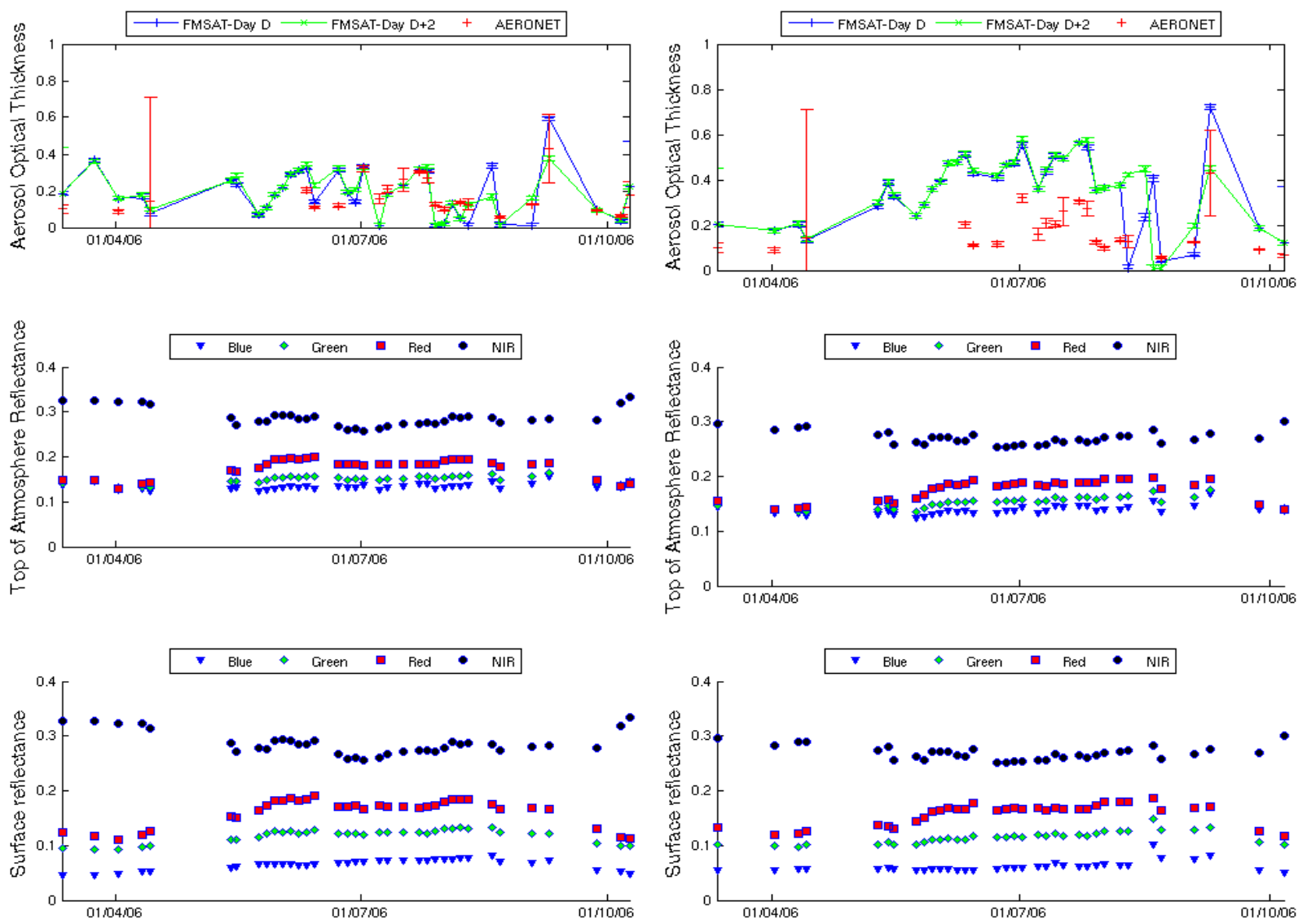

Figure 7: Same as Fig 5 for La Crau data set. Both plots correspond to the "desert" area of the site, but on the left, the neighbourhood used for the inversion expands to an orchard, while on the right, the surface reflectances used in the neighbourhood are very uniform. 


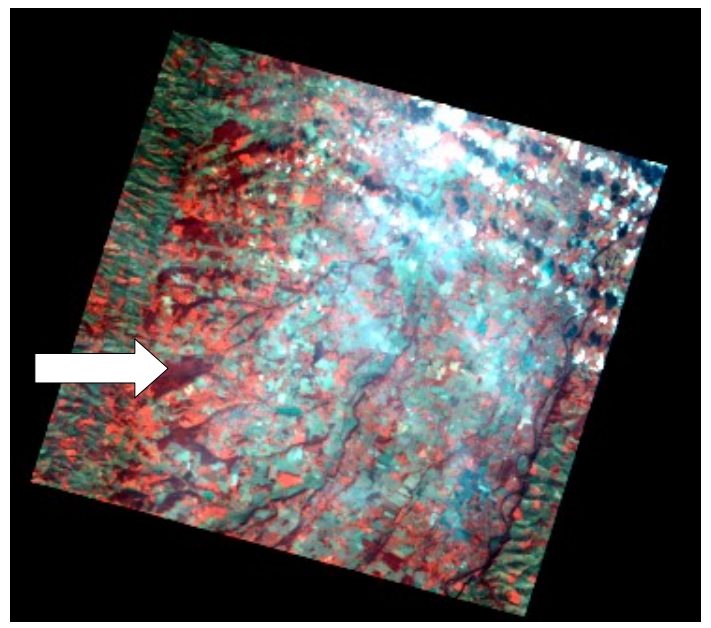

Figure 8: Formosat-2 image (reduced to $100 \mathrm{~m}$ resolution) of the Muret site on November $18^{\text {th }}$ showing semi-transparent clouds in the central part of the image. The white arrow shows the Forest site. 

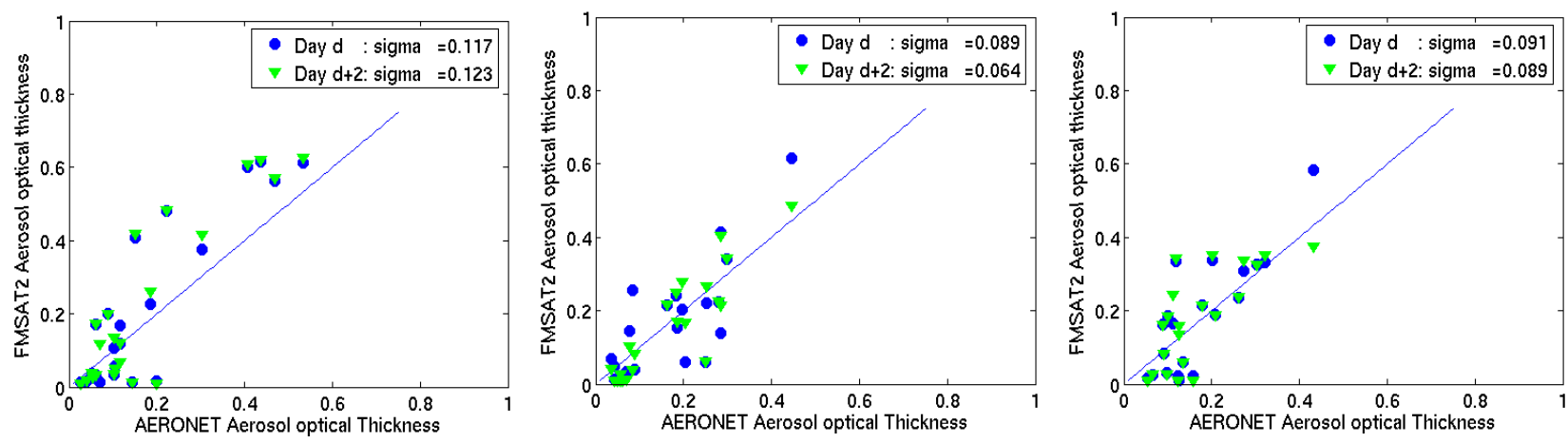

Figure 9: shows the comparison of optical thicknesses derived by our method and by the Aeronet instrument, left for Tensift (Morocco) data set, middle for Muret (France), right for La Crau data set. 

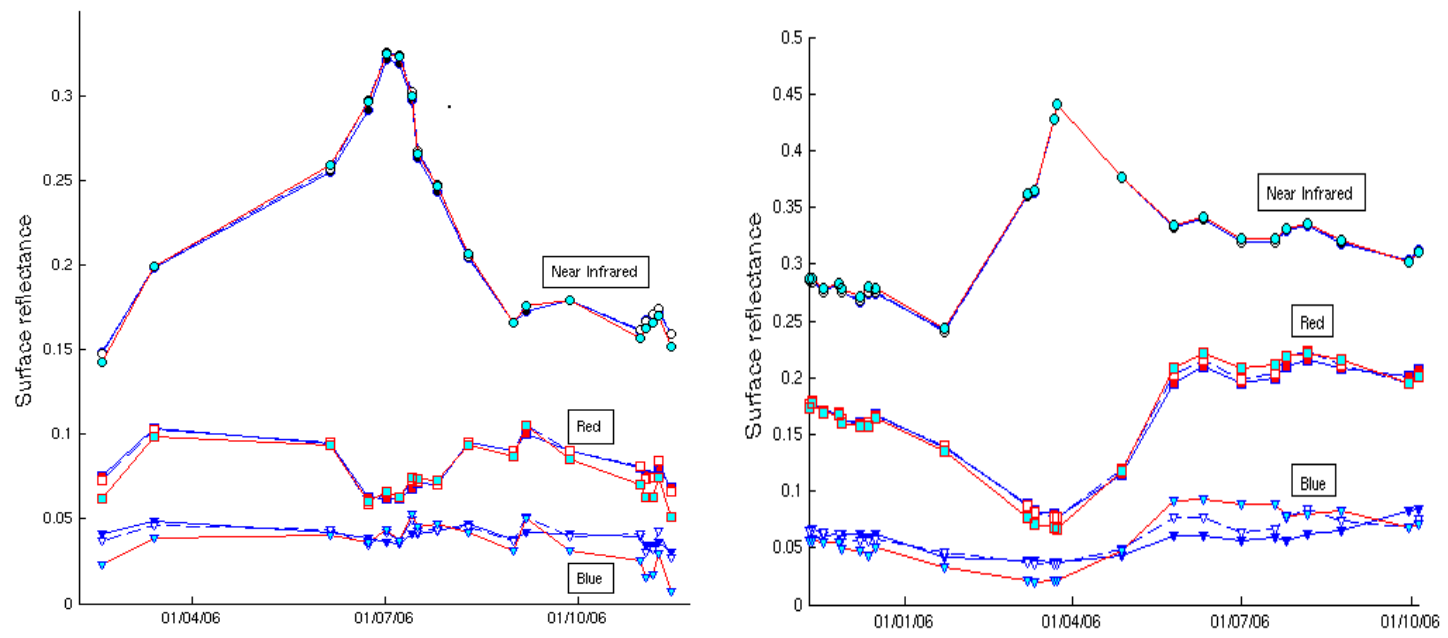

Figure 10: surface reflectances as a function of time for Muret (left), Tensift (Right) for Formosat-2 blue, red, and NIR spectral bands, only for the dates when both Formosat-2 and Aeronet data are available. For each band, the atmospheric correction is performed either with Formosat-2 AOT, (blue line with filled symbols), or with Aeronet AOT (blue dashed line with unfilled symbols), or with a constant AOT (red line with cyan filled symbols). To simplify the figure, the green band is not presented because it often overlaps the red band. 


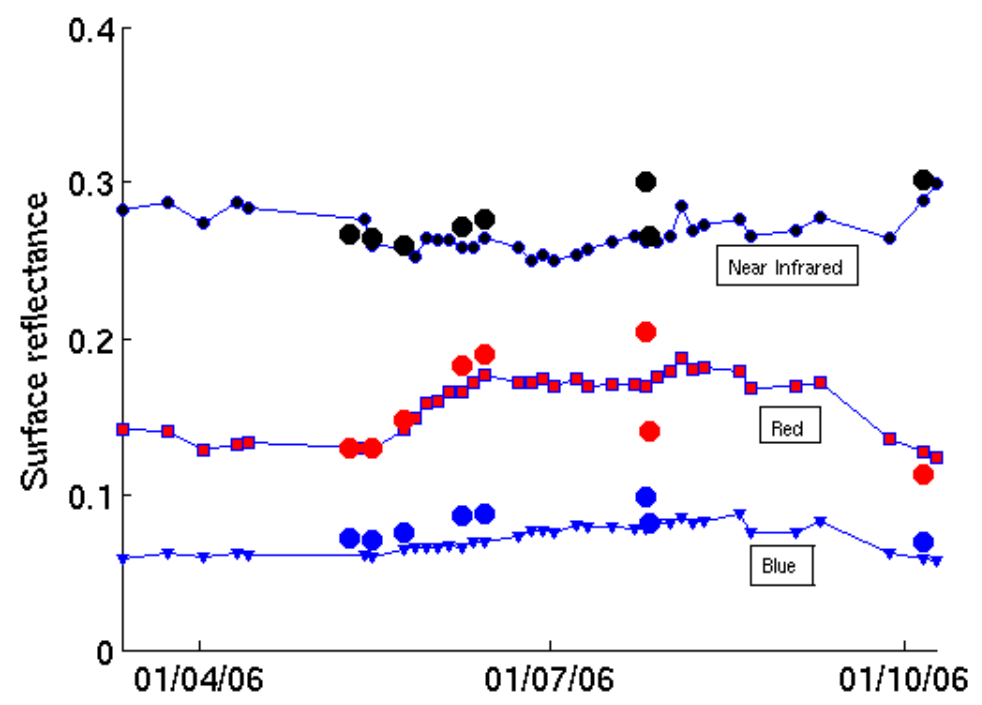

Figure 11: surface reflectances as a function of time at La Crau "desert" site for the blue, red, and NIR spectral bands (lines) compared to in-situ surface reflectances measured by CNES ROSAS automated station 


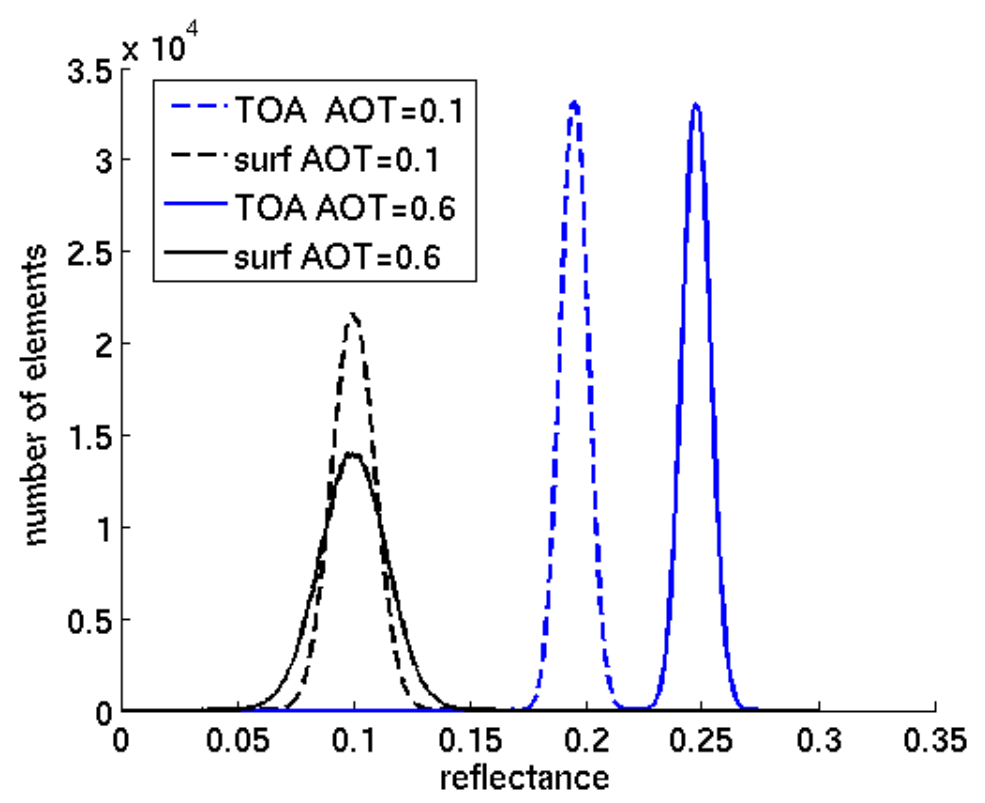

Figure 12: : the blue histograms correspond to 1the result of 500000 simulations of TOA reflectances corresponding to a surface reflectance of 0.1 , for an optical thickness of 0.1 (dashed line) or 0.6 (solid line), with an added Gaussian noise with a standard deviation of 0.015. The black lines correspond to the result of the atmospheric correction and shows a broader surface reflectance histogram when the AOT is 0.6 . 


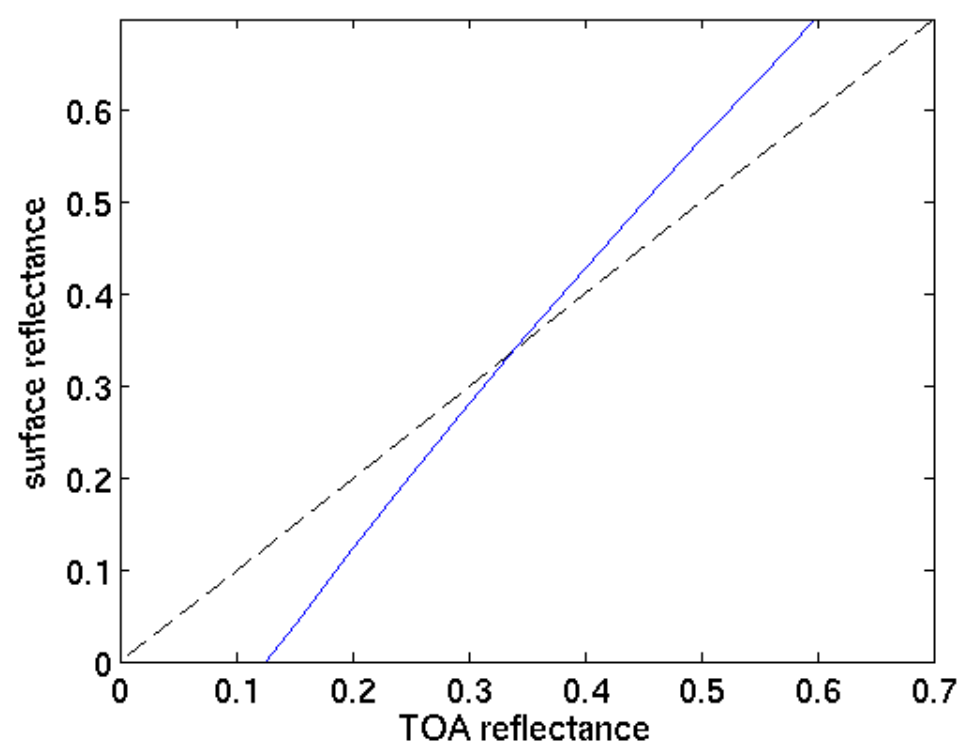

Figure 13: : surface reflectance as a function of TOA reflectance for Formosat2 blue band and for a continental aerosol model with an AOT equal to 0.5. The dashed line is the 1:1 line. 


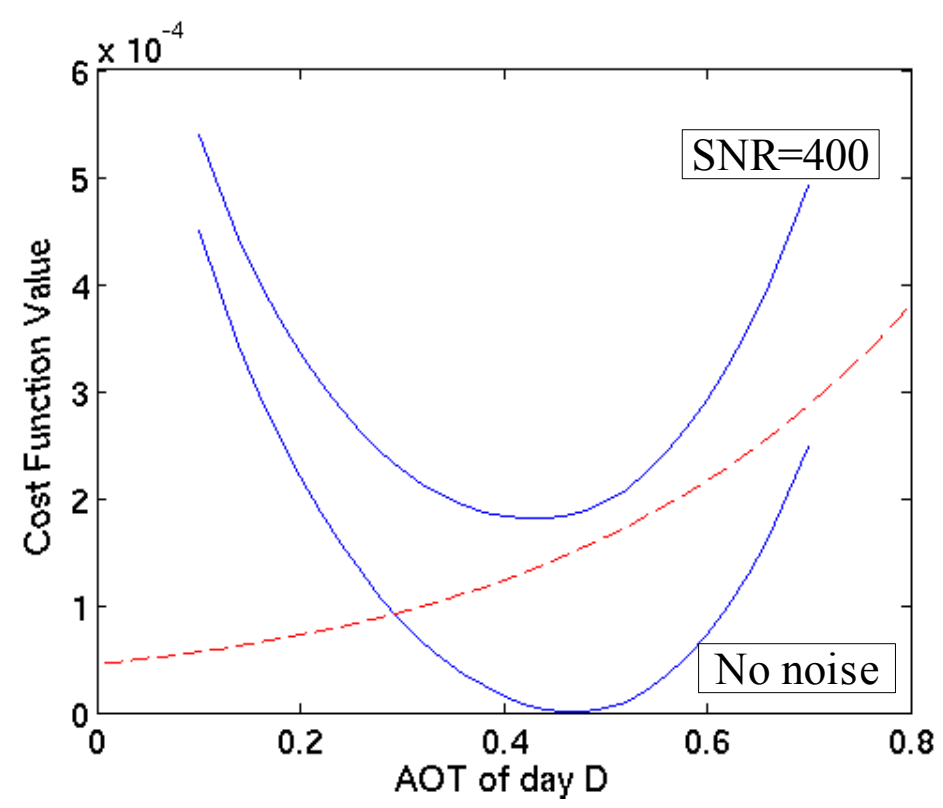

Figure 14: The solid lines show the cost function minimum (as defined in equation 4) as a function of the AOT of day D, for a case without noise and a case with an instrument SNR equal to 400. The dashed line represents the noise added to the cost function because of the instrument SNR. 
Table 1: Error statistics on AOT and surface reflectance as a function of landscape signal to noise ratio. simulations are performed for an instrument signal to noise ratio of 400 at reduced resolution, and several values of landscape SNR.

\begin{tabular}{|c|c|c|c|c|}
\hline $\begin{array}{c}\text { Landscape Signal } \\
\text { to Noise ratio }\end{array}$ & $\begin{array}{c}\text { RMS error } \\
\text { on AOT }\end{array}$ & $\begin{array}{c}\text { Bias on } \\
\text { AOT }\end{array}$ & $\begin{array}{c}\text { RMS error on } \\
\text { green band } \\
\text { surface } \\
\text { reflectance }\end{array}$ & $\begin{array}{c}\text { MS error on NIR } \\
\text { band surface } \\
\text { reflectance }\end{array}$ \\
\hline 50 & 0.053 & -0.075 & 0.0052 & 0.0054 \\
\hline 100 & 0.037 & -0.022 & 0.0026 & 0.0028 \\
\hline 200 & 0.031 & -0.007 & 0.0019 & 0.0016 \\
\hline 400 & 0.030 & -0.004 & 0.0018 & 0.0011 \\
\hline
\end{tabular}


Table 2: study of the sensitivity of AOT retrieval and of atmospheric correction for a few degraded cases

\begin{tabular}{|c|c|c|c|c|}
\hline Case description & $\begin{array}{c}\text { Standard } \\
\text { deviation of } \\
\text { error on AOT }\end{array}$ & Bias on AOT & $\begin{array}{l}\text { RMS error on } \\
\text { green band } \\
\text { surface } \\
\text { reflectance }\end{array}$ & $\begin{array}{l}\text { RMS error on } \\
\text { NIR band } \\
\text { surface } \\
\text { reflectance }\end{array}$ \\
\hline Nominal case & 0.037 & -0.022 & 0.0026 & 0.0028 \\
\hline $\begin{array}{l}\text { Case 1: Different aerosol model for } \\
\text { simulations (mean radius } 0.1 \mu \mathrm{m}) \text { and } \\
\text { AOT inversion (mean radius } 0.07 \mu \mathrm{m})\end{array}$ & 0.042 & -0.114 & 0.0027 & 0.0052 \\
\hline $\begin{array}{c}\text { Different aerosol model for } \\
\text { simulations (mean radius } 0.07 \mu \mathrm{m}) \\
\text { and AOT inversion (mean radius } 0.1 \\
\mu \mathrm{m}\end{array}$ & 0.045 & 0.077 & 0.0023 & 0.0050 \\
\hline $\begin{array}{l}\text { Case 2: lower AOT range } \\
\text { AOT ranging in }[0.1,0.5] \\
\text { instead of }[0.1,0.8]\end{array}$ & 0.050 & -0.027 & 0.0028 & 0.0030 \\
\hline $\begin{array}{l}\text { Case 3: lower AOT values } \\
\text { AOT ranging in }[0.0,0.7] \\
\text { instead of }[0.1,0.8]\end{array}$ & 0.036 & 0.001 & 0.0018 & 0.0028 \\
\hline $\begin{array}{c}\text { Case 4: Only one spectral band for } \\
\text { AOT estimation }\end{array}$ & 0.052 & -0.041 & 0.0037 & 0.0030 \\
\hline Case $5: 5 \%$ bias on sensor calibration & 0.031 & -0.053 & 0.0097 & 0.0203 \\
\hline $\begin{array}{c}\text { Case } 6 \text { : more uniform landscape } \\
\text { LAI ranging in }[0.1,0.5] \\
\text { instead of }[0.1,5]\end{array}$ & 0.052 & -0.072 & 0.0048 & 0.0024 \\
\hline $\begin{array}{c}\text { Case } 7 \text { : brighter landscape } \\
\text { Green reflectance ranging in } \\
{[0.19,0.23]} \\
\text { instead of }[0.09,0.13]\end{array}$ & 0.043 & -0.042 & 0.0020 & 0.0045 \\
\hline
\end{tabular}

